\title{
ELETRODOS FABRICADOS POR "SILK-SCREEN"
}

Valberes B. Nascimento

Departamento de Química - UFRPE - 52171-030 - Recife - PE

Lúcio Angnes

Instituto de Química - USP - 05508-900 - São Paulo - SP

Recebido em 6/11/97; aceito em 12/1/98

\begin{abstract}
SCREEN-PRINTED ELECTRODES. A review dealing with the use of screen-printing technology to manufacture disposable electrodes is presented, covering in details virtually all the publications in the area up to early 1997 and including 206 references. The elements and different strategies on constructing modified electrodes are highlighted. Commercial and Home-made ink recipes are discussed. Microelectrode arrays, built by the combination of photostructuring and screen-printing technologies to the mass production of advanced disposable sensors, are also discussed. Future research trends are predicted.
\end{abstract}

Keywords: screen-printing; disposable; modified electrodes.

\section{INTRODUÇÃO}

Sensibilidade, seletividade, estabilidade, precisão, resposta rápida, facilidade de uso, custo baixo e robustez são as características mais importantes perseguidas no desenvolvimento de sensores. Baixo custo e facilidade de uso são determinantes no desenvolvimento de versões comercializáveis para o público em geral. Na prática, eletrodos sólidos são os mais adequados para fins comerciais.

Se, por um lado as infinitas possibilidades de modificação de eletrodos sólidos permitem visualizar o desenvolvimento dos mais variados sensores para atender a crescente demanda, principalmente nas áreas médica, industrial e ambiental ${ }^{1}$, por outro lado, a regeneração da superfície após o uso é o maior entrave para o desenvolvimento de eletrodos sólidos comerciais. Tratamentos físico e químico-eletroquímico, capazes de regenerar eficazmente a superfície, não são apropriados para sensores comerciais, uma vez que dependem fortemente da "mão do operador". A solução para o problema seria o desenvolvimento de eletrodos descartáveis, que eliminaria a necessidade de regeneração de superfície. Para este fim, o desenvolvimento de membranas descartáveis e eletrodos de pasta de carbono se apresentaram nas últimas décadas como alternativas. No entanto, algumas limitações destas tecnologias, como aquelas relacionadas à lixiviação de componentes da pasta de carbono modificada, com conseqüente perda de atividade e estabilidade do sensor, e a forma artesanal peculiar dos eletrodos de pasta de carbono e de membrana, desfavorecem o emprego destas tecnologias em eletrodos comerciais.

A tecnologia de "screen-printing", mais conhecida como "silk-screen", tem sido empregada com grande sucesso na fabricação de eletrodos nesta última década. Ao mesmo tempo que possibilita a produção em massa de eletrodos a um custo extremamente baixo, é simples e pode ser praticada em qualquer laboratório, sendo pois apropriada para produção de eletrodos descartáveis.

O Eletrodo Impresso (EI), "Screen-Printed Electrode", é simplesmente um filme depositado sobre um suporte inerte, geralmente de PVC ou cerâmica de alumina. Em geral, este filme é parcialmente coberto por uma segunda camada de um isolante para definir uma área de contato elétrico numa extremidade e outra área para ser a superfície do eletrodo na outra extremidade.
Um dos principais aspectos dos EIs, que os tornam extremamente atrativos quando se busca o desenvolvimento de sensores comerciais, é a possibilidade de total automação na fabricação de um sistema completo contendo os eletrodos de trabalho, auxiliar e referência, todos impressos no mesmo suporte. Esta característica, associada à simplicidade de elaboração e às inúmeras possibilidades de modificação dos EIs, promete colocar a técnica numa posição privilegiada entre as demais.

Eletrodos modificados podem ser facilmente elaborados uma vez que os inúmeros artifícios utilizados para modificação dos eletrodos de pasta de carbono se adequam aos EIs. Duas grandes revisões de literatura sobre os eletrodos de pasta de carbono foram publicadas recentemente ${ }^{2,3}$

$\mathrm{O}$ crescente interesse pelo desenvolvimento de EIs pode ser visto na figura 1. Artigos de revisão relacionados diretamente aos EIs ${ }^{1,4-14}$ ou abordando temas correlatos ${ }^{15-18}$ são disponíveis na literatura e podem oferecer ao leitor informações valiosas sobre o assunto.

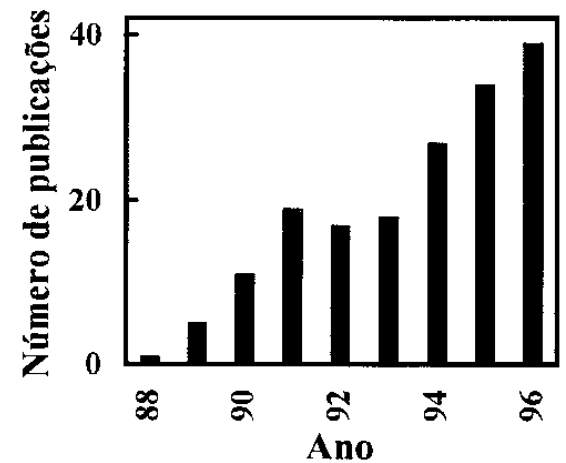

Figura 1. Publicações por ano referentes a eletrodos impressos por "screen-printing".

Este artigo de revisão focaliza o impacto, o papel e as perspectivas futuras dos eletrodos descartáveis fabricados por "screen-printing" na química eletroanalítica. Além disso, tendo em vista ser um assunto pouco conhecido no Brasil, procurouse dar a sua redação um aspecto didático. Em relação aos EIs para gases, vapores e umidade, foi feita apenas uma breve abordagem e citação da literatura. 


\section{PROCESSO DE FABRICAÇÃO DOS ELETRODOS IMPRESSOS}

O processo de "screen-printing", seus equipamentos, materiais e métodos estão muito bem estabelecidos para produção em massa de componentes eletrônicos como capacitores, resistores e condutores em circuitos impressos. Aplicações desta natureza atestam por si só a repetibilidade em espessura e geometria das camadas impressas cuja resolução chega respectivamente a 10 e $100 \mu \mathrm{m}$. Equipamentos modernos automáticos e semi-automáticos são disponíveis no mercado. Na preparação de eletrodos impressos são utilizados esses mesmos equipamentos, materiais e métodos com pequenas adaptações.

Hart \& Wring ${ }^{1}$, num artigo de revisão sobre aplicações de EIs em análises extra-laboratoriais, divulgaram uma lista de endereços de empresas fornecedoras de materiais em geral, máquinas e equipamentos para a preparação de eletrodos pelo processo de "screen-printing".

O processo de "screen-printing" consiste basicamente em forçar a tinta a passar através de uma tela para ser depositada sobre um substrato plano. O desenho definido pelas partes abertas da tela é reproduzido no substrato. Uma combinação do uso sucessivo de diferentes telas e diferentes tintas é normalmente utilizada na preparação dos eletrodos. Em geral, a etapa final de impressão consiste na aplicação de uma camada parcial de um isolante para definir uma área a ser usada como contato elétrico numa extremidade e outra área para ser a superfície do eletrodo na outra extremidade. As figuras 2 e 3 ilustram, respectivamente, o procedimento de preparação dos EIs e o aspecto final de um sensor coberto com um filme de nafion depositado também por "screen-printing".
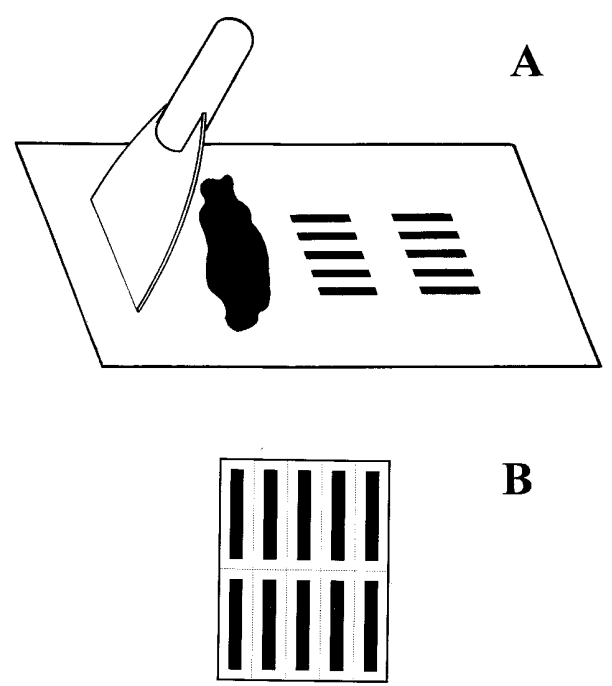

B

Figura 2. (A) Ilustração do processo de "screen-printing" $e$ (B) 10 eletrodos impressos.

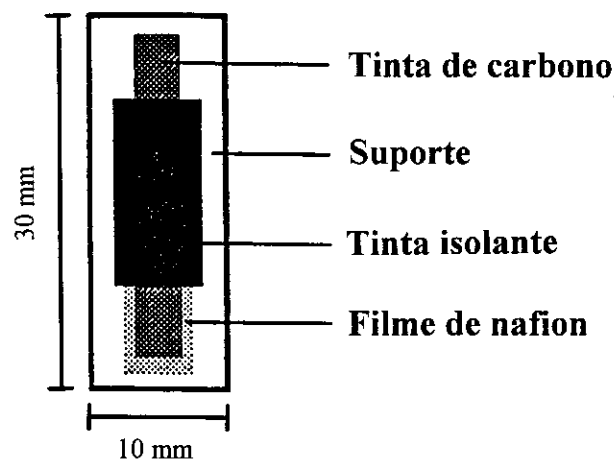

Figura 3. Diagrama esquemático de um eletrodo modificado com um filme de nafion depositado por "screen-printing".
As etapas básicas da confecção de um EI são a preparação ou seleção da tinta, seleção da tela, impressão, secagem e cura. $\mathrm{O}$ processo é repetido para as camadas sucessivas.

A secagem e cura são muitas vezes realizadas numa única etapa em temperaturas que variam desde a temperatura ambiente até $1000^{\circ} \mathrm{C}$. Geralmente o material impresso requer aquecimento para polimerização da tinta antes da camada estar pronta para a próxima etapa de impressão.

Para aumentar a condutividade elétrica do EI, a primeira camada pode ser de uma tinta metálica condutora de Ag, Au, Pt ou outro metal. Neste caso, as camadas sucessoras devem ser posicionadas sobre a trilha metálica para prevenir o contato entre o metal e a solução eletrolítica. Camadas metálicas são também freqüentemente utilizadas para imprimir eletrodos de referência e auxiliar conjuntamente com o eletrodo de trabalho para sistemas de três eletrodos.

\section{MATÉRIA PRIMA PARA CONFECÇÃO DOS ELETRODOS IMPRESSOS}

Para um material ser usado como substrato na confecção de eletrodos voltamétricos necessita geralmente apresentar elevada inércia química e inércia eletroquímica, esta última numa ampla faixa de potenciais; elevado sobrepotencial para produção de hidrogênio e oxigênio; baixa corrente residual; alta condutividade elétrica e propiciar uma fácil regeneração da superfície. Estas características têm levado o carbono a ser amplamente empregado como matéria prima para confecção de eletrodos ${ }^{19}$.

\subsection{Tintas Comerciais}

Tintas condutoras e isolantes comerciais, originalmente desenvolvidas para aplicações na elaboração de circuitos impressos na área da eletrônica, têm se mostrado também apropriadas para serem utilizadas como material base na confecção dos EIs. A maioria dos trabalhos descritos na literatura usa essas tintas. Seus principais componentes são vidros ligantes (aglutinante), como borossilicatos ou aluminossilicatos; solventes, tais como etilcelulose; e aditivos, dependendo da aplicação. Tintas com elevada condutividade, usadas para produção de contatos elétricos, contêm pó de metais tais como Au, Pt, Ag e Pd. Para aplicações especiais, como a produção de resistores, tintas a base de carbono são disponíveis. Após a impressão da tinta no suporte, o filme é secado e usualmente curado a temperaturas que podem chegar a $1000^{\circ} \mathrm{C}$. Através deste processo forma-se um filme duro e aderente, com espessura de 10-20 $\mu \mathrm{m}$, com as propriedades mecânicas e elétricas desejadas ${ }^{6}$. O uso de suportes cerâmicos é bastante adequado quando são necessárias temperaturas altas de cura. Mais recentemente, tintas que requerem temperaturas de cura mais baixas têm sido desenvolvidas usando-se polímeros ao invés de vidros como aglutinante. A composição exata e o processo de fabricação das tintas comerciais fazem parte de patentes e não são inteiramente reveladas. Um estudo comparativo entre quatro tintas comerciais a base de carbono, amplamente utilizadas na confecção de EIs, obtidas de diferentes fabricantes, revelou diferenças no comportamento eletroquímico dos eletrodos confeccionados com as mesmas ${ }^{20}$.

\subsection{Receitas de tintas}

Diante do uso bem sucedido da tecnologia de "screenprinting" na fabricação de eletrodos utilizando tintas condutoras comerciais, originalmente desenvolvidas para outros fins, começaram a surgir novas formulações destinadas especificamente a confecção de EIs. Várias receitas de "home-made inks" (HMIs), como são usualmente chamadas as tintas elaboradas no laboratório, têm sido empregadas na literatura ${ }^{4,21-53}$. A preparação completa da tinta permite o controle da composição e de todas as etapas envolvidas no processo, cuja grande vantagem seria a 
elaboração de formulações com propriedades específicas para viabilizar ou otimizar p. ex. a imobilização de um dado componente biológico no desenvolvimento de biossensores. Eletrodos modificados podem ser elaborados através da modificação dos componentes que vão ser usados na fabricação da tinta ou adicionando aditivos à tinta já preparada, ou mesmo após a impressão do eletrodo pela modificação de sua superfície, usando métodos convencionais. A versatilidade das HMIs pode ser exemplificada no notável aumento de sensibilidade do biossensor para glicose apresentado por Cardosi \& Birch $^{32}$, resultante da imobilização covalente da enzima glicose oxidase em carbono platinizado, o qual foi utilizado como material base para preparação da tinta. Uma receita típica foi apresentada por Hart et $a l .{ }^{26} \mathrm{e}$ consiste na mistura de acetato de celulose, ciclohexanona, acetona e pó de grafite.

\subsection{Propriedades das Tintas}

A composição das HMIs compreende basicamente um material base inerte de elevada condutividade como grafite de alta pureza finamente pulverizado; um aglutinante como o polímero acetato de celulose e um sistema solvente como ciclohexanona-acetona. Além das propriedades químicas e eletroquímicas já mencionadas acima, que um material precisa apresentar para poder servir de base na fabricação de eletrodos em geral, outras características precisam ser consideradas na formulação de uma HMI:

Viscosidade adequada ao processo de "screen-printing". A viscosidade depende intrinsecamente da natureza do aglutinante, da sua dosagem percentual, da presença de aditivos ${ }^{27,54}$ e do sistema solvente utilizado. Esse último deve proporcionar uma volatilidade adequada, baixa o suficiente para prolongar o tempo de evaporação, para facilitar a operação de "screen-printing".

Aderência suficiente para uma fixação efetiva do filme ao suporte. O sistema solvente pode também contribuir para melhorar a aderência do filme ao suporte, especialmente quando este último é levemente corroído pelo solvente.

Flexibilidade para evitar a presença de rachaduras na superfície do eletrodo. Esta característica é mais importante para eletrodos impressos em suportes flexíveis como PVC.

Resistividade elétrica deve ser a mais baixa possível. A resistividade está diretamente relacionada com percentagem de substrato condutor, aglutinante e outros aditivos como enzimas, mediadores etc.. Soluções de compromisso entre os diversos fatores que determinam o desempenho geral do sensor, desde a viscosidade da tinta até p. ex. a atividade enzimática final de um biossensor, devem ser adotadas. Uma resistividade de 250 $\Omega . c m$ foi considerada ótima na elaboração de um biossensor utilizando uma $\mathrm{HMI}^{26}$

A maioria das formulações apresentadas na literatura, com exceção daquelas empregadas para sensores de gases, vapores e umidade, utiliza carbono como material base. Aquela proposta por Hart et $a .^{26}$, que combina o uso de acetato de celulose como aglutinante e ciclohexanona-acetona como sistema solvente, tem sido largamente utilizada na elaboração de biossensores impressos em suporte de PVC ${ }^{24,25,34,35,37-39,43,44,49}$. O sistema solvente assegura uma forte aderência das partículas de grafite ao suporte de PVC: a ciclohexanona contribui para prolongar o tempo de evaporação, enquanto o acetato de celulose proporciona uma superfície de grafite flexível que previne a formação de fissuras se o eletrodo for flexionado levemente. A mesma formulação foi também usada em suporte cerâmico de alumina por outros autores ${ }^{21,30,31}$. Formulações à base de água como solvente têm sido também empregadas ${ }^{4,29,32}$, inclusive para explorar a atividade catalítica de pó de grafite metalizado com $\mathrm{Pt}, \mathrm{Ni}, \mathrm{Cr}, \mathrm{Rh}, \mathrm{Pd}, \mathrm{Ru}$ e $\mathrm{Ag}^{4}$ num estudo que combina tecnologias de materiais catalíticos, procedimentos de imobilização de enzimas, deposição de membranas, "screen-printing" e jato de tinta na construção de biossensores. Nesse trabalho ${ }^{4}$, pó de grafite metalizado, polímero hidroxietilcelulose e solução tampão fosfato pH 7 são misturados para formar a tinta. A enzima glicose oxidase é incorporada ao sensor ou como aditivo à tinta ou através da impressão de uma camada adicional de uma mistura enzima/hidroxietilcelulose. A tecnologia de jato de tinta mostrou-se muito adequada para deposição de uma camada extra de polímero acetato de celulose ou náfion com a finalidade de prevenir a lixiviação dos componentes do biossensor. Outras formulações à base de polivinilpirrolidina $^{22,23,27,40,42,45}$ e hidroxietilcelulose e $^{4,28,40,41,47,48,50-53}$ também têm sido empregadas.

É comum o uso de vidros ligantes na formulação de tintas comerciais em geral ${ }^{6}$, sendo também possível o uso de sílica para ajustar a viscosidade de HMIs ${ }^{27}$. No entanto, emprego mais nobre da sílica pode estar na combinação do processo sol-gel com a tecnologia de "screen-printing". O processo sol-gel consiste basicamente em reações de hidrólise e condensação de alcóxidos de silício com formação de uma estrutura rígida tridimensional de sílica porosa ${ }^{55}$. Uma propriedade muito importante deste processo é o fato da síntese ser realizada a temperatura ambiente e em condições químicas suportáveis por moléculas como enzimas e proteínas ${ }^{56}$. O encapsulamento de espécies químicas e biológicas através do processo sol-gel vem sendo utilizado na elaboração de eletrodos modificados, como o sensor voltamétrico para determinação de traços de níquel por "stripping", que se baseia na formação de um compósito de sol-gel e carbono dopado com dimetilglioxima ${ }^{57}$. Mais recentemente, a elaboração de uma HMI contendo precursores de sol-gel, cujo procedimento de cura envolve um processo sol-gel que aprisiona a enzima glicose oxidase, demonstrou que a combinação do processo sol-gel com a tecnologia de "screenprinting" promete abrir novos horizontes para a produção de sensores eletroquímicos descartáveis ${ }^{46}$.

O uso de HMIs encontra também uma vasta aplicação na elaboração de sensores para gases, vapores e umidade por "screen-printing", que serão abordados na seção 7 .

\section{CARACTERIZAÇÃO DOS ELETRODOS IMPRESSOS}

Vários trabalhos apresentados na literatura são voltados para a caracterização dos EIs ${ }^{4,19,33,42,58-67}$. Alguns artifícios como o uso de filmes, metais platínicos e mediadores de elétrons, largamente usados no desenvolvimento de eletrodos modificados, são também empregados nessas investigações.

Como complemento aos estudos eletroquímicos fundamentais, a microscopia eletrônica de varredura (MEV) tem sido de grande importância em estudos de superfície dos EIs, sendo utilizada por alguns autores na tentativa de encontrar relações entre a morfologia superficial dos eletrodos e seu desempenho eletroquímico. Um exame minucioso das micrografias pode revelar detalhes específicos relacionados, p. ex., às diferenças no procedimento de preparação do sensor ou a um dado tratamento ou componente particular ${ }^{19,33}, 42,58-62,64,65$. MEV pode então proporcionar informações valiosas, seja para um melhor entendimento do comportamento eletroquímico do sensor ou mesmo para documentar topografias superficiais típicas obtidas sob certas condições experimentais empregadas em sua preparação.

A eficiência de processos de deposição de filmes químicos e biológicos foi avaliada por $\mathrm{MEV}^{62}$ num estudo voltado para o desenvolvimento de um sensor descartável de glicose.

EIs a base de platina apresentam características eletroquímicas similares aos eletrodos de disco de platina comerciais ${ }^{64}$. A principal diferença está no comportamento microscópico, típico de microeletrodos, verificados por cronocoulometria e voltametria em experimentos realizados em curto domínio de tempo. Esta característica foi associada a elevada porosidade da superfície do eletrodo, examinada por MEV. Similarmente, 
eletrodos de filme elaborados a partir de uma mistura grafiteepoxy também se comportam como uma rede de microdiscos de grafite ${ }^{19}$. MEV revela a existência de uma superfície rugosa contendo micropartículas de grafite distribuídas aleatoriamente na superfície do epoxy. A rugosidade da superfície contribui para inibir a sobreposição de camadas de difusão radial, prevista para experimentos realizados em largo domínio de tempo, e reforça a predominância do comportamento de microeletrodo esperado teoricamente.

MEV tem sido também de enorme utilidade no desenvolvimento de sensores que se baseiam num EI coberto por uma membrana. Uma nova técnica de imobilização enzimática, que consiste numa pasta enzimática polimerizável por luz UV, adequada para produzir uma membrana através do processo de "screen-printing", foi desenvolvida por Bilitweski et al. ${ }^{33}$. O desenvolvimento ${ }^{59}$ e aplicações ${ }^{58,61}$ de redes de microeletrodos, manufaturadas através de perfurações num filme fotossensível pré-depositado, utilizando raio laser e fotomáscaras, são também exemplos nos quais a MEV tem sido de grande importância nos estudos de caracterização dos EIs.

Em sensores para gases, a sensibilidade é fortemente dependente da rugosidade da superfície, tamanho dos grãos, espessura e porosidade do filme. Condições de preparação tais como temperatura de cura e espessura do filme influenciam grandemente a morfologia superficial dos EIs e são pois, fundamentais no desenvolvimento destes sensores. Mochida et al. ${ }^{65}$ verificaram uma forte relação entre estrutura superficial e desempenho eletroquímico, através da análise de micrografias obtidas por MEV, num sensor de gás sulfídrico que combina tecnologias de "screen-printing" e "sputtering".

Diversos estudos de caracterização dos EIs, como os discutidos a seguir, baseiam-se exclusivamente em experimentos eletroquímicos.

Fogg et al. ${ }^{66}$ mostraram que a presença de uma membrana de poli-l-lisina facilita a redução de hexacianoferrato(III) e a re-oxidação do hexacianoferrato(II) diminuindo significativamente o sobrepotencial envolvido no processo, melhorando assim a reversibilidade dos processos eletroquímicos nos EIs. A membrana de poli-L-lisina adere mais fortemente em superfícies rugosas, como aquelas dos EIs, do que em superfícies polidas tais como aquelas de eletrodos de carbono vítreo.

Tendo em vista que os metais platínicos atuam como catalisadores na oxidação eletroquímica de peróxido de hidrogênio e de vários compostos orgânicos importantes, estes metais são utilizados em EIs modificados para reduzir o sobrepotencial de processos eletroquímicos ${ }^{4,27,30-33,40,46,48,50,60,63,64,68-83}$. Muitos autores recorrem a este efeito catalítico em busca de um aumento de seletividade na elaboração de métodos de determinação eletroanalíticos. A presença desses metais causa também um aumento na área superficial do eletrodo ${ }^{63}$.

$\mathrm{O}$ uso de mediadores de elétrons é outro recurso bastante usado na elaboração de EIs modificados $22-26,28,30,35,36,38-40,42-$ $44,49,62,67,73-75,77,84-99$. Os mediadores cobalto-ftalocianina $24-26,35$, $38,39,43,44,49,62,67,87,90,91,94,95$ e derivados de ferroceno ${ }^{22-24,35}$, $39,42,49,93,96,97$ são os mais comumente utilizados. Na maioria dos casos o mediador é misturado diretamente à tinta a ser utilizada na fabricação dos eletrodos. Em alguns procedimentos o mediador é imobilizado na superfície de um EI base. Um exemplo é a imobilização simultânea de dois mediadores, tetracianoquinodimetano e dimetilferroceno, para promover uma conexão elétrica direta do centro redox FAD da enzima glicose oxidase à superfície de um EI. Esta estratégia foi utilizada por Kishimoto $^{42}$ no desenvolvimento de um biossensor amperométrico para glicose que apresenta uma rápida e eficiente transferência de elétrons, acarretando respostas de corrente em potenciais de trabalho extremamente baixos e conseqüentemente mais seletivos. E mais, sua resposta amperométrica não é afetada pela flutuação da concentração de oxigênio dissolvido, uma vez que o mesmo não participa da reação devido à presença do mediador, permitindo o uso do biossensor para medir glicose numa gota de amostra de soro sem nenhum pré-tratamento.

Eletrodos com diferentes janelas de potencial, sensibilidades e correntes residuais foram obtidos a partir de tintas comerciais a base de carbono largamente empregadas para fabricação de EIs $^{20}$. Essas diferenças, atribuídas às composições das tintas, revelaram que a escolha da tinta deveria depender da aplicação eletroanalítica específica e da técnica utilizada.

\section{ELETRODOS IMPRESSOS NÃO MODIFICADOS}

A elaboração de eletrodos modificados descartáveis é sem dúvida o objetivo mais nobre do emprego da tecnologia de "screen-printing" na fabricação de eletrodos. No entanto, alguns trabalhos da literatura mostram que o uso de EIs não modificados representa uma alternativa extremamente atraente ao uso de eletrodos convencionais de mercúrio, carbono vítreo, metais nobres e pasta de carbono em eletroanálise. E mais, o formato planar e a facilidade de miniaturização destes eletrodos são bastante apropriados para sua integração a pequenos equipamentos portáteis.

Nos últimos anos, o uso consagrado do eletrodo de gota pendente de mercúrio, ou de filmes de mercúrio sobre carbono vítreo ou sobre metais nobres, principalmente na famosa análise de metais pesados por "stripping", começou a ser substituído com vantagens pelo uso dos EIs livres de mercúrio, o que é extremamente importante do ponto de vista ambiental quando se pensa em eletrodos descartáveis. EIs não modificados foram usados com sucesso na análise por "stripping" de Zn, $\mathrm{Cd}, \mathrm{Pb}$ e $\mathrm{Cu}^{100} ; \mathrm{Au}(\mathrm{III})^{101}$; e $\mathrm{Cu}(\mathrm{II})^{102}$. EIs cobertos com filme de ouro depositado in situ foram propostos para análise por "stripping" potenciométrico do próprio mercúrio ${ }^{103}$ e de chumbo em urina e água potável ${ }^{104}$. Como será visto adiante, na discussão dos eletrodos modificados, a fabricação de EIs a partir de tintas previamente modificadas com ligantes e resina trocadora de cátions oferece uma ótima alternativa ao uso de eletrodos de mercúrio. No entanto, como era de se esperar, o uso de filme de mercúrio eletrodepositado in situ sobre EIs tem se mostrado útil para a análise por "stripping" de traços de metais pesados ${ }^{58,60,61,105,106}$ e de urânio ${ }^{107}$

EIs não modificados foram também utilizados em estudos de caracterização de inibidores enzimáticos ${ }^{108}$ e determinação automática de lactose ${ }^{109}$ em análise por injeção em fluxo; em estudos comparativos do comportamento eletroquímico de hidroquinona em EIs e em eletrodos convencionais ${ }^{110}$; e na determinação de DNA e RNA por "stripping"111.

Um eletrodo do tipo Clark miniaturizado, para monitoramento transcutâneo de oxigênio, confeccionado por "screenprinting", foi proposto por Harsáni et al. ${ }^{112}$. Cha et al. ${ }^{79}$ mostraram que o uso de Pt minimiza a interferência entre eletrodos, numa rede de EIs em formato de pente, na determinação de oxigênio. A utilização de uma rede de EIs em forma de microbandas permitiu a obtenção de voltamogramas hidrodinâmicos tridimensionais, de oxidação e de redução para reações reversíveis, num único experimento ${ }^{113}$. Um estudo comparativo do desempenho eletroquímico de EIs não modificados foi realizado em nosso grupo recentemente ${ }^{20}$.

\subsection{Célula eletroquímica descartável}

Reagentes impressos proporcionam novas possibilidades no desenvolvimento de sensores eletroquímicos.

Uma notável aplicação da tecnologia de "screen-printing" em eletroquímica está presente na célula eletroquímica descartável (CED) desenvolvida pela Unilever Research ${ }^{114,115}$, patenteada sob o nome "Capillary Fill Device". Trata-se de uma microcélula de camada delgada na qual a solução em análise é introduzida por capilaridade. Sua principal vantagem é possuir um volume constante pré-definido, que dispensa a 
calibração individual. Uma distância de 100 a $200 \mu \mathrm{m}$ separa as faces internas da célula. Na base, a face cerâmica contém EIs de trabalho, referência e auxiliar. No topo, a face de vidro contém um coquetel de reagentes, também impressos, que ficam posicionados justamente defronte ao eletrodo de trabalho e disponíveis para serem solubilizados pela própria solução da amostra no momento da análise. Embora todos os reagentes envolvidos sejam descartados juntamente com a célula após uma única medição, isto não inviabiliza o processo por se tratar de microquantidades. Dada a possibilidade de se combinar toda versatilidade dos EIs com uma célula eletroquímica que, além de ser descartável, dispensa a adição de reagentes, o uso de CEDs promete ampliar enormemente as possibilidades de desenvolvimento de sensores descartáveis. E mais, o uso de eletrodos não modificados confere às CEDs um caráter universal, bastando para isso substituir os reagentes impressos.

Enquanto a lixiviação do mediador de elétrons é um grande problema no desenvolvimento de inúmeros biossensores, cuja solução é optar por um mediador que possa ser mantido imobilizado juntamente com a enzima, o uso de mediadores solúveis é um pré-requisito para os biossensores que utilizam CEDs. O líquido em análise, ao penetrar na célula, dissolve os reagentes dispersando-os por todo o volume da microcâmara de reação. Após um intervalo de tempo preestabelecido, é então realizada a medição eletroquímica por voltametria, amperometria ou coulometria.

Um biossensor coulométrico para glicose, contendo um coquetel de reagentes (acetato de celulose, ciclohexanona, mediador hexamin-Ru(III), diidrogenofosfato de potássio, monoidrogenofosfato de potássio, cloreto de potássio, enzima glicose oxidase, citrato ou outro anti-coagulante sanguíneo) impresso na face de vidro defronte ao eletrodo de trabalho numa CED, foi desenvolvido por Turner et al. ${ }^{9}{ }^{75}$. Similarmente, Fogg et al. utilizaram CEDs para construir sensores voltamétricos para nitrato $^{116}$ e fosfato ${ }^{117}$.

\section{ELETRODOS IMPRESSOS MODIFICADOS}

Até o início da década de 70 somente eletrodos inertes tais como mercúrio, carbono, ouro e platina, eram utilizados em química eletroanalítica, quando então se percebeu que a modificação da superfície inerte do eletrodo poderia conduzir a elaboração de um verdadeiro arsenal de sensores para as mais variadas aplicações. Modificar um eletrodo consiste em atribuir e controlar novas propriedades físico-químicas a um eletrodo inerte através do acoplamento de espécies químicas ativas a sua superfície $^{118}$. O sensor resultante pode então consistir de várias camadas sucessivas, depositadas sobre o eletrodo base.

Quanto às possibilidades de modificações, os EIs se assemelham aos eletrodos de pasta de carbono, uma vez que, em princípio, todos os artifícios utilizados para modificação dos eletrodos de pasta de carbono se adequam aos EIs. Os processos de modificação de eletrodo mais comuns envolvem deposição de filme de mercúrio, metais platínicos, complexos metálicos, enzimas, mediadores de elétrons e polímeros. As funções de cada um desses modificadores são muito bem estabelecidas e estudadas em detalhes na literatura. Todos estes processos têm sido aplicados com sucesso também aos eletrodos fabricados pela tecnologia de "screen-printing".

A eletrodeposição de um filme de mercúrio sobre um eletrodo inerte lhe confere propriedades do eletrodo de gota pendente de mercúrio, favorecendo o emprego de eletrodos sólidos em análise de metais pesados por "stripping". Catalisadores metálicos, geralmente metais platínicos na forma de pó de carbono metalizado, bem como diversos complexos metálicos, misturados diretamente à tinta de carbono antes da etapa de impressão, ou depositados sobre a superfície de um EI, têm como função principal baixar o sobrepotencial do processo de óxido-redução da espécie de interesse. Um dos papéis fundamentais das enzimas nos biossensores é o inerente reconhecimento molecular, que permite ao sensor, dentro de certos limites, "enxergar" a espécie de interesse e ser "cego" em relação às demais.

O reconhecimento molecular se dá através da catálise enzimática na superfície do sensor, que promove a ocorrência de reações não eletródicas no sítio ativo da enzima, liberando ou consumindo substâncias eletroativas justamente na superfície do eletrodo base. A resposta analítica do biossensor ou é proveniente da medição eletroquímica destas espécies eletroativas, cuja concentração é função da concentração da espécie de interesse, ou do sinal de oxidação (ou de redução) direta do sítio ativo da enzima a seu estado fundamental. Como os sítios ativos de diversas enzimas óxido-redutases são situados muito internamente em suas estruturas tridimensionais, tais enzimas não podem entrar em contato elétrico direto com a camada inerte do sensor, mesmo estando em contato físico com esta camada $^{2}$. Este contato elétrico pode ser estabelecido através de mediadores de elétrons. O papel do mediador de elétrons é pois, estabelecer uma espécie de contato elétrico entre o sítio ativo da enzima e a camada inerte do sensor, através do seguinte mecanismo: o mediador sofre um processo redox no sítio ativo da enzima, reconduzindo-a a seu estado fundamental, para em seguida sofrer um processo redox inverso na superfície do eletrodo, sendo também reconduzido a seu estado fundamental, completando um ciclo que restaura a enzima e o mediador. O mediador se comporta pois, como uma espécie de mensageiro "que conta ao eletrodo inerte" o que se passou no interior da enzima. Assim, o uso de mediadores tem sido de extrema importância para viabilizar ou otimizar o desenvolvimento de diversos biossensores. E mais, a dopagem do eletrodo com mediadores de elétrons, bem como metais platínicos, é um recurso amplamente usado para aumentar a seletividade em biossensores amperométricos, uma vez que a presença do catalisador ou do mediador possibilita um potencial de trabalho numa região mais próxima de zero volts, mais imune a interferências de outras espécies eletroativas. Quanto aos polímeros, cuja principal função tem sido o aprisionamento de espécies químicas e biológicas na superfície do eletrodo, as propriedades físicas e químicas dos filmes poliméricos resultantes têm sido paralelamente aproveitadas para realizar funções que vão desde a seletividade (através da exclusão de interferentes por tamanho ou por carga elétrica) até a mediação de elétrons dos sítios ativos da própria enzima quando imobilizada no polímero. A barreira difusional estabelecida pela presença do filme polimérico é também um recurso usado para ampliar a linearidade de resposta do sensor a concentrações mais altas do analito. $\mathrm{O}$ grande interesse pelo uso de eletropolimerização advém da facilidade de aprisionar espécies químicas e biológicas e de controlar a quantidade de material depositado, que por sua vez ocorre apenas na superfície eletroativa. Assim, préconcentração, reconhecimento molecular, eletrocatálise, filmes e barreiras difusionais são recursos importantes na elaboração de novos sensores. Combinações destes recursos, que alguns autores costumam chamar de coquetéis, têm inclusive dado origem a biossensores comerciais.

A Tabela 1 apresenta uma coletânea dos EIs modificados apresentados na literatura, excetuando os sensores de estado sólido para gases, vapores e umidade. Esta tabela reúne estratégias e detalhes dos mais variados métodos de modificação empregados. Percebe-se uma predominância no desenvolvimento de sensores para glicose, seguida à distância por lactose e pesticidas. O excepcional desempenho da amperometria é atestado por ser a técnica preferida em cerca de $85 \%$ dos casos. Em complementação a Tabela 1 poderíamos citar outros EIs para glicose s2,119-126, lactato $^{47,51,127}$, pesticidas , $^{53,128-}$ 130 e salicilato ${ }^{131}$. A análise de traços tem sido também favorecida com o desenvolvimento de novos EIs contendo ligantes $^{132}$ e até mesmo resinas trocadoras de íons ${ }^{133,134}$ que oferecem uma nova alternativa ao uso de eletrodos de mercúrio. 


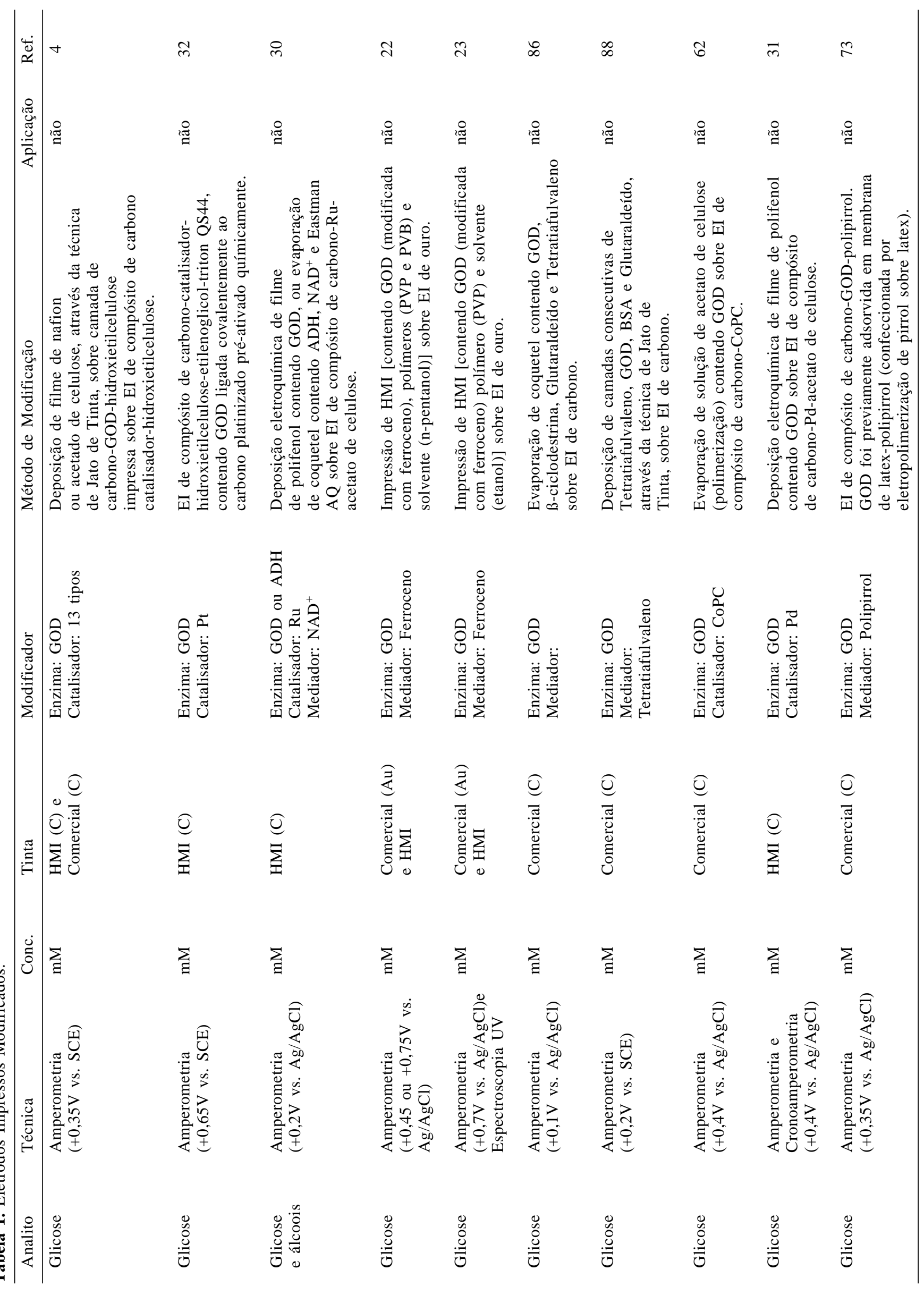




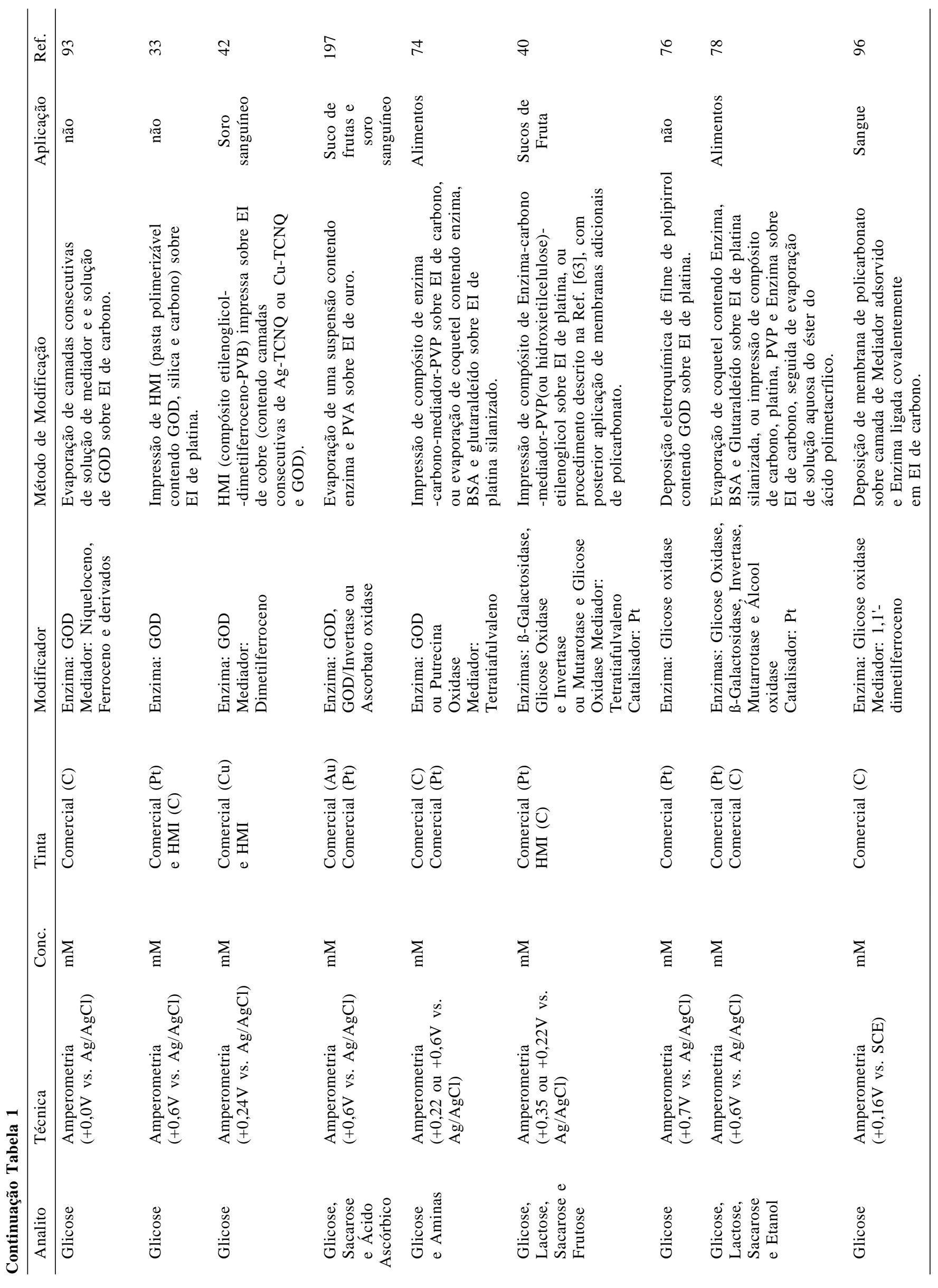




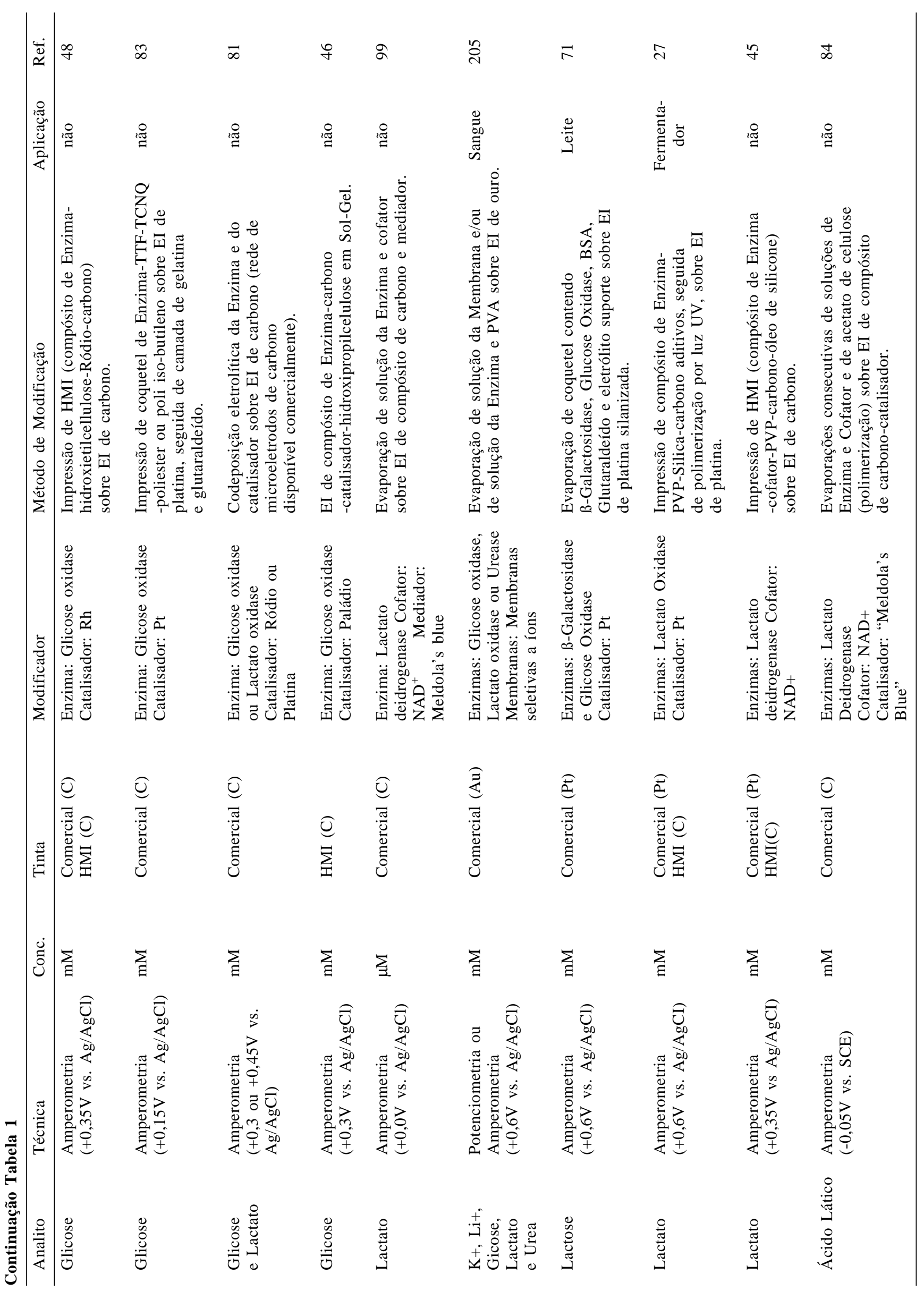




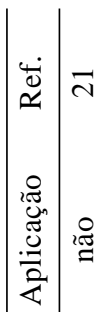

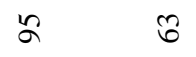
$\stackrel{a}{2}$

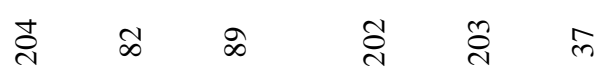

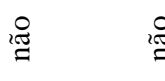

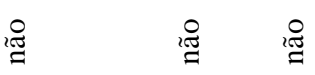

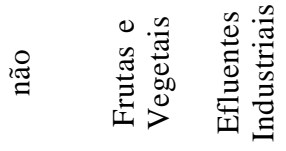

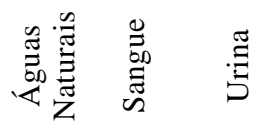

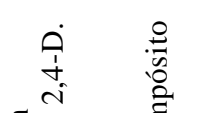

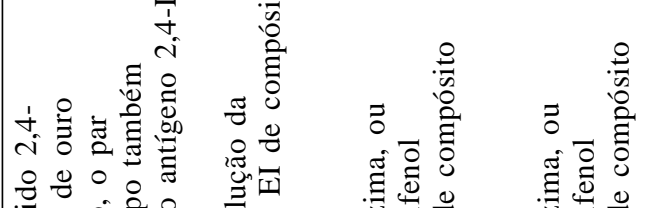

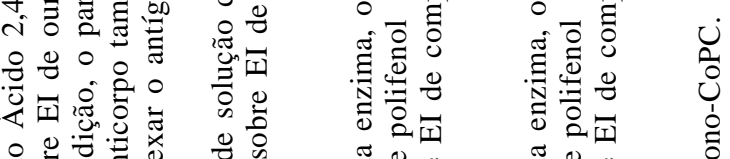

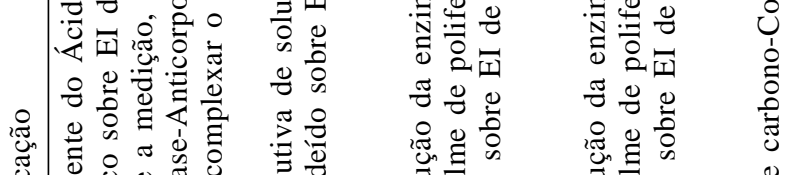
त)

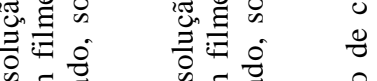

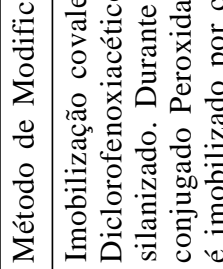

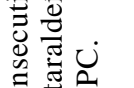

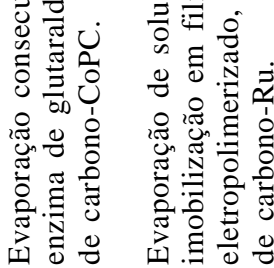

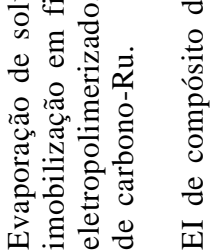

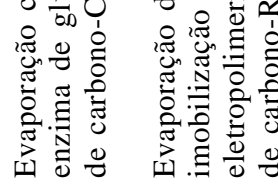

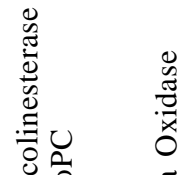

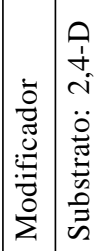<smiles>OC(O)O</smiles>

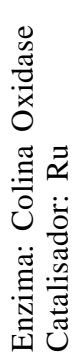

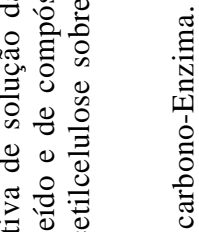
可

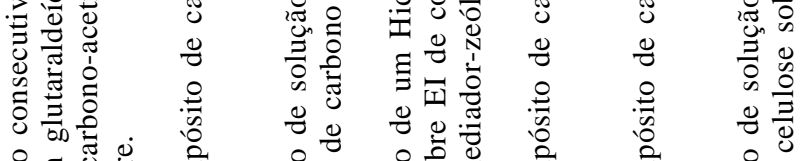

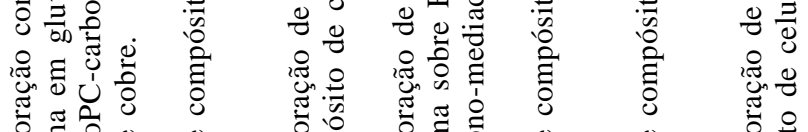

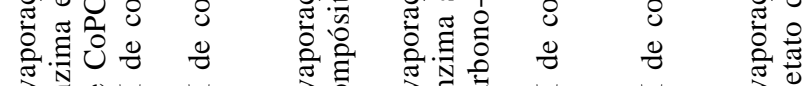

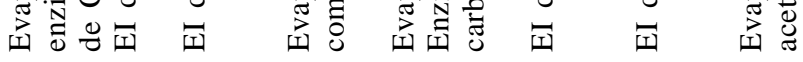

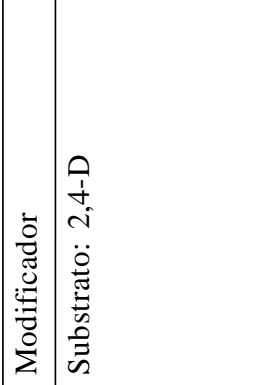

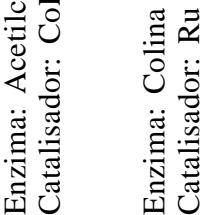

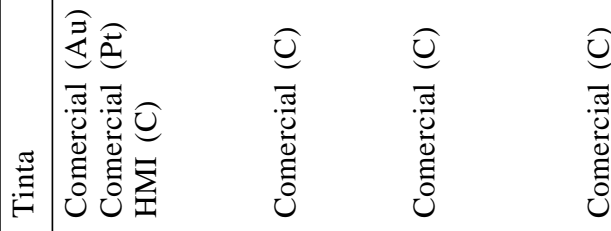

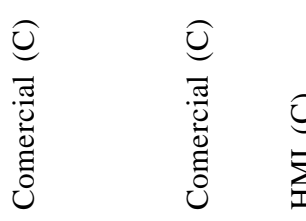

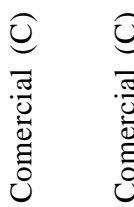

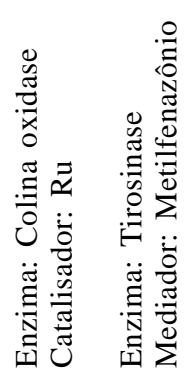

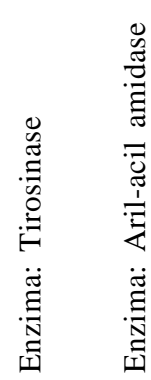

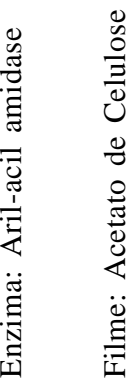

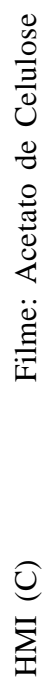
ن்
$\sum$
ミ
ミ ฏ
ミ ミ

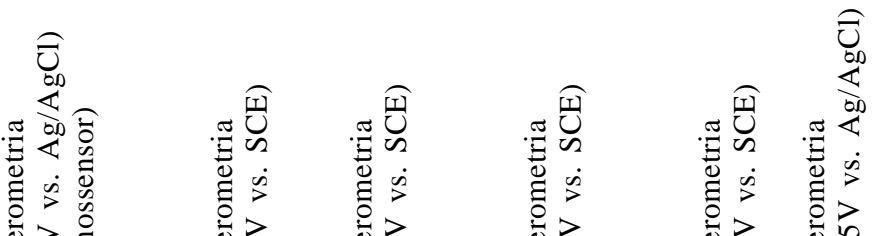

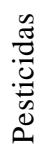

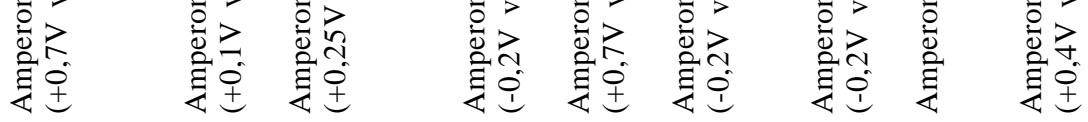

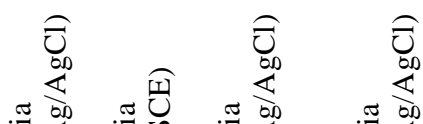

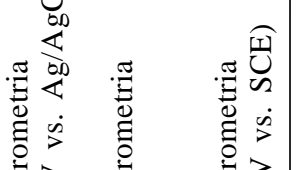

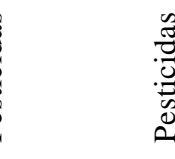

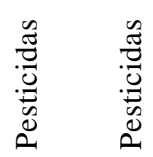

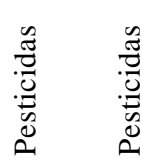

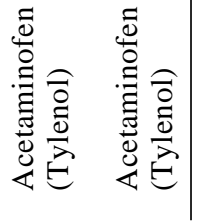




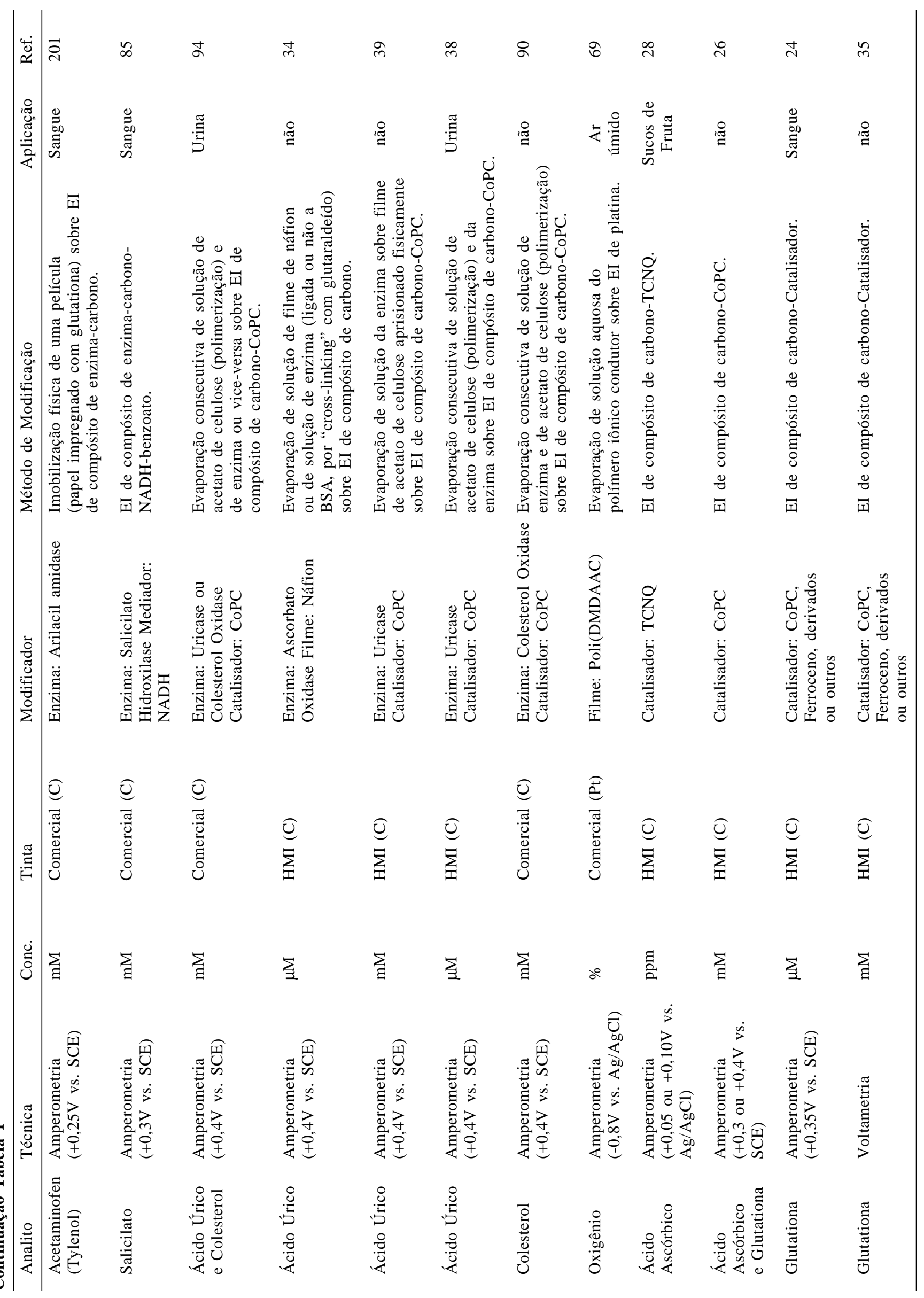




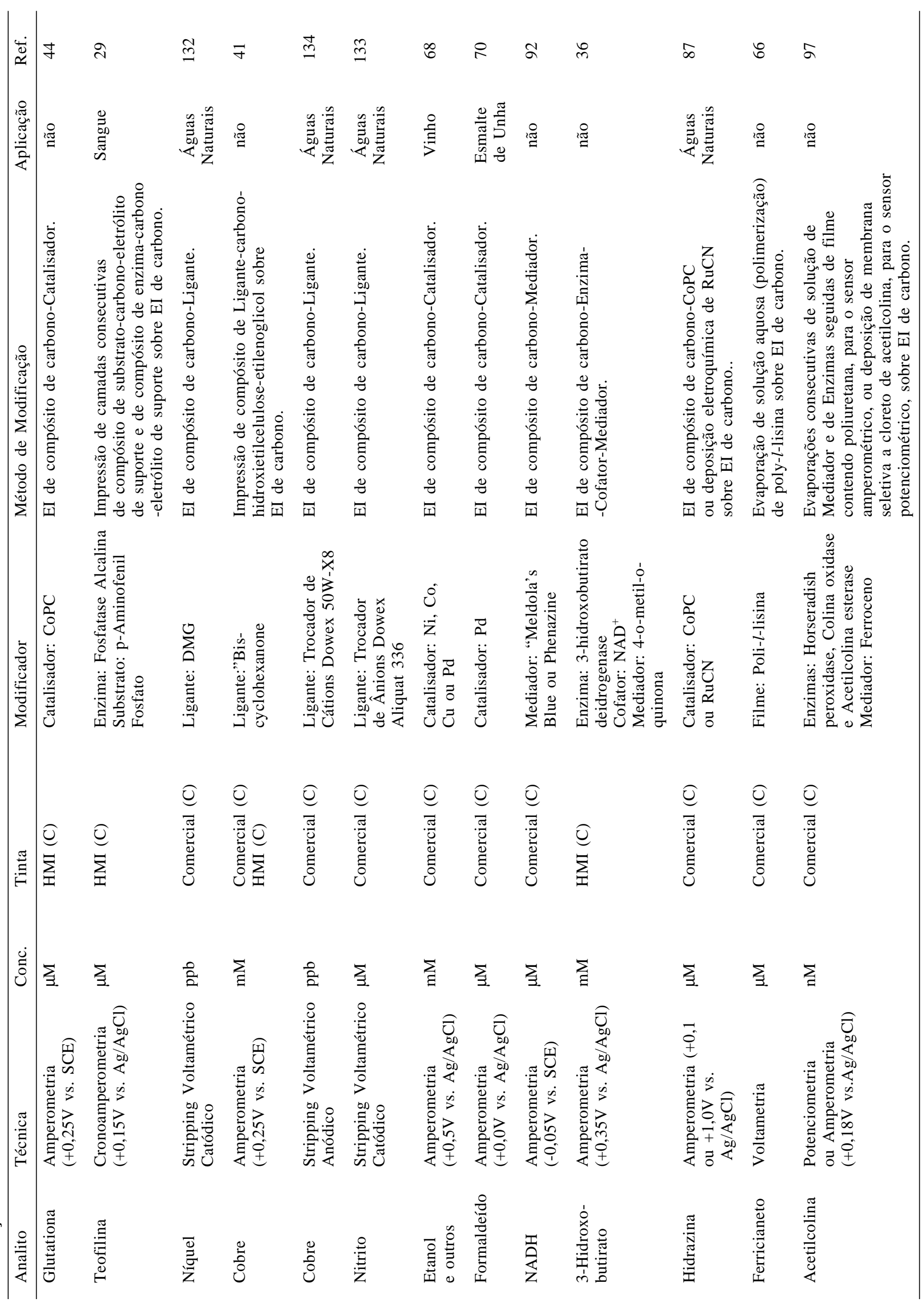


Uma consulta à tabela 1 colocará o leitor a par dos principais elementos e estratégias que vêm sendo utilizados na elaboração de EIs modificados.

\section{SENSORES PARA GASES, VAPORES E UMIDADE}

A tecnologia de "screen-printing" encontra larga aplicação no desenvolvimento de sensores de estado sólido para gases, vapores e umidade sem adição de eletrólito de suporte. Nestes sensores, a área do eletrodo desempenha um papel fundamental na sensibilidade. Para obtenção de uma superfície com estrutura tridimensional porosa e de elevada área de contato, o processo de cura é efetuado a altas temperaturas visando expulsar o ligante da pasta. Menil et al. ${ }^{135}$ propuseram uma rota para a preparação de sensores para gases onde consideram inclusive a possibilidade de se aumentar a sensibilidade do sensor aplicando pressão mecânica para imprimir um filme isento de ligante, ao invés de eliminar o ligante na etapa de cura do processo convencional.

Os EIs para gases, vapores e umidade são geralmente condutimétricos e usam $\mathrm{SnO}_{2}$ como material base. O sensor completo contém um par de eletrodos metálicos sobre ou sob o filme sensível ao analito, e um aquecedor no lado oposto, todos impressos num único suporte inerte. A sensibilidade e seletividade do sensor dependem intrinsecamente da natureza do filme sensível e da temperatura de operação.

A tecnologia de "screen-printing" é as vezes utilizada em conjunto com outras tecnologias ${ }^{136-143}$. Lampe et al. ${ }^{137}$, p. ex., utilizaram "sputtering" reativo para o desenvolvimento da superfície sensível e "screen-printing" para os eletrodos e para o aquecedor, enquanto Lee \& Choi $^{143}$ utilizaram "screen-printing" para o desenvolvimento da superfície sensível e evaporação a vácuo para os eletrodos. Tieman \& Heineman ${ }^{69}$ elaboraram um sensor amperométrico para oxigênio utilizando um polímero hidrofílico para eliminar a adição de eletrólito de suporte. Neste último caso se faz necessário a presença de eletrodos de referência e auxiliar também impressos no sensor.

Há um grande número de publicações recentes explorando a tecnologia de "screen-printing" para o desenvolvimento de sensores eletroquímicos de gases como oxigênio ${ }^{69,112,141,144-146}$, gás sulfídrico ${ }^{65,147-153}$, gás carbônico ${ }^{139,144,146,154,155}$, monóxido de carbono ${ }^{137,140,146,153}$, 156-167, hidrogênio ${ }^{144,159,167-170}$, hidrocarbonetos $135,143,146,157,159,160,162,163,171-176$, óxidos de nitrogênio $^{136,161,163}$, amônia ${ }^{177}$ e fosfina ${ }^{135}$; de vapores de álcoois ${ }^{138,156,}$ 157,178-182 e tetracloreto de carbono ${ }^{183}$ e de umidade en, $^{158,184-190}$.

\section{REDES DE MICROELETRODOS FABRICADAS POR TECNOLOGIA DE "SCREEN-PRINTING"}

O interesse na aplicação de microeletrodos em química analítica está relacionado a suas propriedades únicas tais como maior eficiência no transporte de massa, menor tempo de resposta, reduzida queda ôhmica e melhor relação sinal-ruído em comparação com eletrodos de tamanho convencional. Estas propriedades derivam de suas dimensões e da predominância de difusão radial em eletrodos de raio micrométrico ou submicrométrico $^{191-193}$.

A dificuldade de construção de microeletrodos é apontada como a razão principal de sua baixa popularidade. Entre os diversos procedimentos de confecção apresentados na literatu$\mathrm{ra}$, destacam-se aqueles que possibilitam a preparação de redes de microeletrodos. Numa rede, as propriedades de cada microeletrodo individual são preservadas enquanto as correntes medidas correspondem à soma das contribuições individuais, evitando assim a necessidade de grande amplificação de corrente. Algumas redes são multicanais, ou seja, permitem o controle individual de cada eletrodo ou de grupos de eletrodos. Recentemente, foi desenvolvido em nosso laboratório um dos procedimentos mais simples de fabricação de redes multicanais de 
microeletrodos de ouro $(25 \mu \mathrm{m}$ de diâmetro) que pode ser praticado em laboratórios em geral ${ }^{194,} 195$.

$\mathrm{O}$ enorme desenvolvimento da tecnologia planar de filmes finos, especialmente para produção de circuitos integrados em substratos de silício, tem proporcionado os avanços mais significativos na fabricação de redes de eletrodos em forma de microdiscos regulares de extrema qualidade dimensional ${ }^{6,196}$. No entanto, as diversas etapas de química úmida envolvidas nos processos de microlitografia limitam muito suas aplicações no desenvolvimento de sensores ${ }^{59}$. E mais, os equipamentos empregados em microlitografia para os processos de deposição tais como "sputtering", são comuns apenas a laboratórios especializados de microeletrônica.

Redes de microeletrodos podem ser produzidas utilizando-se tecnologias de filmes espessos. Segundo Brainina \& Bond ${ }^{19}$, um eletrodo de filme espesso de grafite-epoxy comporta-se de forma similar a uma rede de microdiscos de grafite distribuídos aleatoriamente numa superfície da resina epoxy e apresenta todas a propriedades de microeletrodo teoricamente previstas.

A tecnologia de "screen-printing" combinada com a polimerização a vácuo de uma camada de material dielétrico, seguida por um processo de fotoabrasão do dielétrico com raio laser (utilizando uma fotomáscara para definir o contorno dos eletrodos), foi empregada com sucesso na preparação de redes de microeletrodos contendo 1000-3000 microdiscos em suporte plástico ${ }^{59}$. Uma rede de microeletrodos de carbono, produzida comercialmente por um processo similar a esta última, foi aplicada como eletrodo descartável no monitoramento de metais pesados em análise de campo ${ }^{61}$. Análise rápida de traços de chumbo com baixos limites de detecção foi realizada utilizando uma rede de 287 microeletrodos de filme de mercúrio (15-35 $\mu \mathrm{m}$ de diâmetro), baseada nesta mesma rede comercial de eletrodos ${ }^{58}$. Naturalmente, a tecnologia de "screen-printing" também se aplica à elaboração de redes de eletrodos de tamanho convencional ${ }^{197,198}$. Scholze et al. ${ }^{197}$ desenvolveram uma rede multicanal de EIs de tamanho convencional $(1,5 \mathrm{~mm}$ de diâmetro), modificados individualmente com diferentes enzimas, ajustável a um soquete eletrônico de 28 pinos, que possibilita a determinação simultânea de glicose, sacarose e ácido ascórbico. Redes de microeletrodos de bandas podem ser também facilmente confeccionadas por "screen-printing"113,199.

\section{CONCLUSÕES}

A crescente demanda por sensores descartáveis e equipamentos portáteis para a descentralização de análises químicas exige o emprego de tecnologias de produção em massa. Embora nenhuma tecnologia tenha sido ainda aceita como majoritária na elaboração de eletrodos descartáveis, o uso de "screenprinting" vem crescendo em popularidade e pode se tornar uma técnica padrão, particularmente devido a sua simplicidade e adequação a laboratórios em geral. Os EIs apresentam excelente desempenho analítico e reúnem as características de modificação de eletrodos sólidos em geral e de eletrodos de pasta de carbono (o modificador pode ser incorporado à tinta), além de serem compatíveis com instrumentos miniaturizados e portáteis. Eletrodos de referência e auxiliar podem também ser impressos, o que facilita a elaboração de pequenas células eletroquímicas como as CEDs. A confecção de redes de microeletrodos pode ser efetuada, p. ex., cobrindo o EI com um filme isolante e em seguida efetuando perfurações nesse filme com raio laser. Todos estes procedimentos foram altamente beneficiados com conhecimentos herdados da área de circuitos impressos, cujos novos avanços deverão contribuir ainda mais no desenvolvimento de eletrodos descartáveis.

O uso dos eletrodos tradicionais de gota pendente de mercúrio, ou de filmes de mercúrio sobre carbono vítreo ou sobre metais nobres, principalmente na famosa análise de metais pesados por "stripping", vem sendo substituído pelo uso dos
EIs livres de mercúrio, o que é extremamente importante do ponto de vista ambiental quando se pensa em eletrodos descartáveis. O sucesso da incorporação de ligantes ${ }^{132}$ e até mesmo resinas trocadoras de íons ${ }^{133,134}$ à tinta, abre novas e largas possibilidades para a análise de traços. O uso de apenas um, dois ou mais eletrodos por muitos químicos em geral, seja durante pesquisas para desenvolvimento de novos métodos eletroanalíticos ou de novos sensores ou mesmo em trabalhos de rotina, pode vir a ser substituído brevemente pelo uso de dezenas, centenas ou mais EIs descartáveis.

A associação de tecnologias de produção em massa com recursos de modificação de eletrodos, tais como incorporação de materiais catalíticos, mediadores, membranas e enzimas, já resultaram no desenvolvimento de inúmeros sensores descartáveis, como o biossensor de glicose para pacientes diabéticos ${ }^{96,200}$ disponível comercialmente. No entanto, os resultados alcançados até o presente momento indicam que os maiores avanços ainda estão por vir com a pesquisa de novas formulações de tintas, com propriedades específicas para viabilizar ou otimizar p. ex. a imobilização de determinados componentes biológicos no desenvolvimento de novos biossensores. A formulação de HMIs que incorporam processos sol-gel é um exemplo das grandes possibilidades a serem melhor exploradas nesta área.

\section{AGRADECIMENTOS}

Os autores agradecem ao CNPq e a CAPES/PICD pelo suporte financeiro concedido a este projeto e a Profa. Silvia Helena Pires Serrano pela leitura do manuscrito e valiosas observações.

\section{REFERÊNCIAS}

1. Hart, J. P.; Wring, S. A.; Electroanalysis 1994, 6, 617.

2. Gorton, L.; Electroanalysis 1995, 7, 23.

3. Kalcher, K.; Kauffmann, J.-M.; Wang, J.; Svancara, I.; Vytras, K.; Neuhold, C.; Yang, Z.; Electroanalysis 1995, 7, 5.

4. Newman, J. D.; White, S. F.; Tothill, I. E.; Turner, A. P. F.; Anal. Chem. 1995, 67, 4594.

5. Hilditch, P. I.; Green, M. J.; Analyst 1991, 116, 1217.

6. Alvarez-Icaza, M.; Bilitewski, U.; Anal. Chem. 1993, 65, 525A.

7. Green, M. J.; Hilditch, P. I.; Anal. Proc. 1991, $28,374$.

8. Frew, J. E.; Green, M. J.; Anal. Proc. 1989, $26,334$.

9. Cardosi, M. F.; Turner, A. P. F.; In The Diabetes Annual, Ed. Alberti, K. G. M. M. and Krall, L. P., Elsevier, Amsterdam, 1990, vol. 5, p. 254.

10. Chemnitius, G. C.; Cammann, K.; Analysis Europa 1996, $30,33$.

11. Skladal, P.; Macholan, L.; Chemicke Listy 1997, 91, 105.

12. Hart, J. P.; Wring, S. A.; Trends Anal. Chem. 1997, 16, 89.

13. Goldberg, H. D.; Brown, R. B.; Liu, D. P.; Meyerhoff, M. E.; Sens. Actuators 1994, B21, 171.

14. Galan-Vidal, C. A.; Munoz, J.; Dominguez, C.; Alegret, S.; Trends Anal. Chem. 1995, 14, 225.

15. Scheller, F.; Schubert, F.; Pfeiffer, D.; Hintsche, R.; Dransfeld, I.; Renneberg, R.; Wollenberger, U.; Riedel, K.; Pavlova, M.; Kühn, M.; Müller, H. G.; Tan, P. M.; Hoffmann, W.; Moritz, W.; Analyst 1989, 114, 653.

16. Green, M. J.; Hill, H. A. O.; J. Chem. Soc., Faraday Trans. 1986, 82, 1237.

17. Deshpande, S. S.; Rocco, R. M.; Food Technol. 1994, $6,146$.

18. Davis, J.; Vaughan, D. H.; Cardosi, M. F.; Enz. Microb. Technol. 1995, 17, 1030.

19. Brainina, Kh. Z.; Bond, A. M.; Anal. Chem. 1995, 67, 2586

20. Wang, J.; Tian, B.; Nascimento, V. B.; Angnes, L.; Electrochim. Acta. 1998, (in press).

21. Kaláb, T.; Skládal, P.; Anal. Chim. Acta 1995, 304, 361. 
22. Nagata, R.; Clark, S. A.; Yokoyama, K.; Tamiya, E.; Karube, I.; Anal. Chim. Acta 1995, 304, 157.

23. Nagata, R.; Yokoyama, K.; Durliat, H.; Comtat, M.; Clark, S. A.; Karube, I.; Electroanalysis 1995, 7, 1027.

24. Wring, S. A.; Hart, J. P.; Analyst 1992, 117, 1281.

25. Skládal, P.; Anal. Chim. Acta 1992, 269, 281.

26. Wring, S. A.; Hart, J. P.; Bracey, L.; Birch, B. J.; Anal. Chim. Acta 1990, 231, 203.

27. Rohm, I.; Genrich, M.; Collier, W.; Bilitewski, U.; Analyst 1996, $121,877$.

28. Kulys, J.; Costa, E. J. D.; Anal. Chim. Acta 1991, 243, 173.

29. Foulds, N. C.; Wilshere, J. M.; Green, M. J.; Anal. Chim. Acta 1990, 229, 57.

30. Wang, J.; Chen, Q.; Pedrero, M.; Pingarron, J. M.; Anal. Chim. Acta 1995, 300, 111.

31. Wang, J.; Chen, Q.; Analyst 1994, 119, 1849.

32. Cardosi, M. F.; Birch, S. W.; Anal. Chim. Acta 1993, 276, 69.

33. Rohm, I.; Künnecke, W.; Bilitewski, U.; Anal. Chem. 1995, 67, 2304.

34. Gilmartin, M. A. T.; Hart, J. P.; Birch, B.; Analyst 1992, 117, 1299.

35. Wring, S. A.; Hart, J. P.; Birch, B. J.; Analyst 1991, 116, 123.

36. Batchelor, M. J.; Green, M. J.; Sketch, C. L.; Anal. Chim. Acta 1989, 221, 289.

37. Gilmartin, M. A. T.; Hart, J. P.; Analyst 1994, 119, 2431.

38. Gilmartin, M. A. T.; Hart, J. P.; Analyst 1994, 119, 833.

39. Gilmartin, M. A. T.; Hart, J. P.; Birch, B. J.; Analyst 1994, 119, 243.

40. Bilitewski, U.; Jäger, A.; Rüger, P.; Weise, W.; Sens. Actuators 1993, B15-16, 113.

41. Somasundrum, M.; Bannister, J. V.; Sens. Actuators 1993, B15-16, 203.

42. Kishimoto, Y.; Sens. Actuators 1994, B20, 225.

43. Hart, J. P.; Wring, S. A.; Anal. Proc. 1991, 28, 4.

44. Wring, S. A.; Hart, J. P.; Birch, B. J.; Electroanalysis 1992, 4, 299.

45. Yoon, H. C.; Kim, H. S.; Anal. Chim. Acta 1996, 336, 57.

46. Wang, J.; Pamidi, P. V. A.; Park, D. S.; Anal. Chem. 1996, 68, 2705

47. Collier, W. A.; Janssen, D.; Hart, A. L.; Biosens. Bioelectron. 1996, 11, 1041.

48. White, S. F.; Tothill, I. E.; Newman, J. D.; Turner, A.P.F.; Anal. Chim. Acta 1996, 321, 165.

49. Gilmartin, M. A. T.; Ewen, R. J.; Hart, J. P.; J. Electroanal. Chem. 1996, 401, 127.

50. Kröger, S.; Turner, A. P. F.; Anal. Chim. Acta 1997, 347, 9.

51. Hart, A. L.; Cox, H.; Janssen, D.; Biosens. Bioelectron. 1996, 11,833 .

52. Marcinkeviciene, J.; Kulys, J.; Biosens. Bioelectron. 1993, 8, 209.

53. Kulys, J.; Costa, E. D. J.; Biosens. Bioelectron. 1991, 6, 109.

54. Hower, R. W.; Shin, J. H.; Cha, G. S.; Meruva, R. K.; Meyerhoff, M. E.; Brown, R. B.; Sens. Actuators 1996, B33, 168 .

55. Buckley, A. M.; Greenblatt, M.; J. Chem. Ed. 1994, 71, 599.

56. Avnir, D.; Braun, S.; Lev, O.; Ottolenghi, M.; Chem. Mater. 1994, 6, 1605.

57. Wang, J.; Pamidi, P. V. A.; Nascimento, V. B.; Angnes, L.; Electroanalysis 1997, 9, 689.

58. Feldman, B. J.; D’Alessandro, A.; Osterloh, J. D.; Hata, B. H.; Clin. Chem. 1995, 41, 557.

59. Seddon, B. J.; Shao, Y.; Girault, H. H.; Electrochim. Acta 1994, 39, 2377.

60. Wang, J.; Tian, B.; Anal. Chem. 1992, 64, 1706.

61. Wang, J.; Lu, J.; Baomin, T.; Yarnitzky, C.; J. Electroanal. Chem. 1993, 361, 77.

62. Gilmartin, M. A. T.; Hart, J. P.; Patton, D. T.; Analyst 1995, 120, 1973.
63. Cagnini, A.; Palchetti, I.; Mascini, M.; Turner, A. P. F.; Mikrochim. Acta 1995, 121, 155.

64. Tieman, R. S.; Igo, D. H.; Heineman, W. R.; Johnson, J.; Seguin, R.; Sens. Actuators 1991, B5, 121.

65. Mochida, T.; Kikuchi, K.; Kondo, T.; Ueno, H.; Matsuura, Y.; Sens. Actuators 1995, B24-25, 433.

66. Fogg, A. G.; Pirzad, R.; Moreira, J. C.; Davies, A. E.; Anal. Proc. 1995, 32, 209.

67. Gilmartin, M. A. T.; Ewen, R. J.; Hart, J. P.; Honeybourne, C. L.; Electroanalysis 1995, 7, 547.

68. Wang, J.; Pedrero, M.; Pamidi, P. V. A.; Cai, X.; Electroanalysis 1995, 7, 1032.

69. Tieman, R. S.; Heineman, W. R.; Anal. Lett. 1992, 25, 807.

70. Wang, J.; Pedrero, M.; Cai, X.; Analyst 1995, 120, 1969.

71. Jager, A.; Bilitewski, U.; Analyst 1994, 119, 1251.

72. Cagnini, A.; Palchetti, I.; Lionti, I.; Mascini, M.; Turner, A. P. F.; Sens. Actuators 1995, B24-25, 85.

73. Koopal, C. G. J.; Bos, A. A.C. M.; Nolte, R. J. M.; Sens. Actuators 1994, B18-19, 166.

74. Bilitewski, U.; Chemnitius, G. C.; Rüger, P.; Schmid, R. D.; Sens. Actuators 1992, B7, 351.

75. Morris, N. A.; Cardosi, M. F.; Birch, B. J.; Turner, A. P. F.; Electroanalysis 1992, 4, 1.

76. Foulds, N. C.; Lowe, C. R.; J. Chem. Soc. Faraday Trans. 1986, 82, 1259.

77. McNeil, C. J.; Spoors, J. A.; Cooper, J. M.; Alberti, K. G. M. M.; Mullen, W. H.; Anal. Chim. Acta 1990, 237, 99.

78. Schmidt, A.; Rohm, I.; Rüger, P.; Weise, W.; Bilitewski, U.; Fresenius' J. Anal. Chem. 1994, 349, 607

79. Cha, C. S.; Shao, M. J.; Liu, C. C.; Sens. Actuators 1990, B2, 239.

80. Chemnitius, G. C.; Bilitewski, U.; Sens. Actuators 1996, B32, 107.

81. Wang, J.; Chen, Q.; Anal. Chem. 1994, 66, 1007.

82. Palchetti, I.; Cagnini, A.; Carlo, M. D.; Coppi, C.; Mascini, M.; Turner, A. P. F.; Anal. Chim. Acta 1997, 337, 315.

83. Khan, G. F.; Electroanalysis 1997, 9, 325.

84. Sprules, S. D.; Hart, J. P.; Wring, S. A.; Pittson, R.; Anal. Chim. Acta 1995, 304, 17.

85. Frew, J. E.; Bayliff, S. W.; Gibbs, P. N. B.; Green, M. J.; Anal. Chim. Acta 1989, 224, 39.

86. Chen, Q.; Pamidi, P. V. A.; Wang, J.; Kutner, W.; Anal. Chim. Acta 1995, 306, 201.

87. Wang, J.; Pamidi, P. V. A.; Talanta 1995, 42, 463.

88. Newman, J. D.; Turner, A. P. F.; Marrazza, G.; Anal. Chim. Acta 1992, 262, 13.

89. Kotte, H.; Gründig, B.; Vortop, K-D.; Strehlitz, B.; Stottmeister, U.; Anal. Chem. 1995, 67, 65.

90. Gilmartin, M. A. T.; Hart, J. P.; Analyst 1994, 119, 2331.

91. Hart, J. P.; Hartley, I. C.; Analyst 1994, 119, 259.

92. Sprules, S. D.; Hart, J. P.; Wring, S. A.; Pittson, R.; Analyst 1994, 119, 253.

93. Atanasov, P.; Kaisheva, A.; Gamburzev, S.; Iliev, I.; Sens. Actuators 1992, B8, 59.

94. Gilmartin, M. A. T.; Hart, J. P.; Anal. Proc. 1995, 32, 341.

95. Hartley, I. C.; Hart, J.P.; Anal. Proc. 1994, 31, 333.

96. Cass, A. E. G.; Davis, G.; Francis, G. D.; Hill, H. A. O.; Aston, W. J.; Higgins, I. J.; Plotkin, E. V.; Scott, L. D. L.; Turner, A. P. F.; Anal. Chem. 1984, 56, 667.

97. Kataky, R.; Parker, D.; Analyst 1996, 121, 1829.

98. Sprules, S. D.; Hartley, I. C.; Wedge, R.; Hart, J. P.; Pittson, R.; Anal. Chim. Acta 1996, 329, 215.

99. Sprules, S. D.; Hart, J. P.; Pittson, R.; Wring, S. A.; Electroanalysis 1996, 8, 539.

100. Desmond, D.; Lane, B.; Alderman, J.; Hall, G.; Alvarez Icaza, M.; Garde, A.; Ryan, J.; Barry, L.; Svehla, G.; Arrigan, D. W. M.; Schniffner, L.; Sens. Actuators 1996, B34, 466.

101. Wang, L. Z.; Zhang, Y. T.; Fenxi Huaxue 1996, 24, 285. 
102. Wang, L. Z.; Zhang, Y. T.; Fenxi Huaxue 1994, 22, 1185. 103. Wang, J.; Tian, B.; Anal. Chim. Acta 1993, 274, 1.

104. Wang, J.; Tian, B.; Anal. Chem. 1993, 65, 1529.

105. Wang, J.; Analyst 1994, 119, 763.

106. Wang, J.; Lu, J.; Yarnitzky, C.; Anal. Chim. Acta 1993, $280,61$.

107. Wang, J.; Baomin, T.; Setiadji, R.; Electroanalysis 1994, $6,317$.

108. Günther, A.; Bilitewski, U.; Anal. Chim. Acta 1995, 300, 117.

109. Mayer, M.; Genrich, M.; Kuennecke, W.; Bilitewski, U.; Anal. Chim. Acta 1996, 324, 37.

110. McAlernon, P.; Slater, J. M.; Anal. Proc. 1994, 31, 365.

111. Wang, J.; Cai, X.; Tian, B.; Shiraishi, H.; Analyst 1996, 121,965 .

112. Harsáni, G.; Péteri, I.; Deák, I.; Sens. Actuators 1994, B18-19, 171.

113. Chao, M. H.; Huang, H. J.; Anal. Chem. 1997, 69, 463.

114. Birch, B. J.; Burns, I. W.; Int. Pat. Appl. PCT/WO88/ 04048, 1988.

115. Shanks, I. A.; Smith, A. M.; Nylander, C. I.; Int. Pat. Appl. PCT/WO86/00138, 1986.

116. Fogg, A. G.; Scullion, S. P.; Edmonds, T. E.; Birch, B. J.; Analyst 1991, 116, 573.

117. Fogg, A. G.; Scullion, S. P.; Edmonds, T. E.; Birch, B. J.; Analyst 1990, 115, 1277.

118. Souza, M. F. B.; Química Nova 1997, 20, 191.

119. Stephens, S. K.; Tothill, I. E.; Warner, P. J.; Turner, A. P. F.; Water Res. 1997, 31, 41.

120. Nagata, R.; Yokoyama, K.; Clark, S. A.; Karube, I.; Biosens. Bioelectron. 1995, 10, 261.

121. Kawagari, M.; Yoshioka, T.; Nankai, S.; Denki Kagaku Oyobi Kogyo Butsuri Kagaku 1990, 58, 1119.

122. Tothill, I. E.; Newman, J. D.; White, S. F.; Turner, A. P. F.; Enz. Microb. Technol. 1997, 20, 590.

123. Bilitewski, U.; Rüger, P.; Schmid, R. D.; Biosens. Bioelectron. 1991, 6, 369.

124. Atanasov, P.; Kaisheva, A.; Lliev, L.; Razumas, V.; Kulys, J.; Biosens. Bioelectron. 1992, 7, 361.

125. Rüger, P.; Bilitewski, U.; Schmid, R. D.; Sens. Actuators 1991, B4, 267.

126. Bartlett, P. N.; Birkin, P. R.; Anal. Chem. 1994, 66, 1552.

127. Hart, A. L.; Turner, A. P. F.; Hopcroft, D.; Biosens. Bioelectron. 1996, 11, 263.

128. Skladál, P.; Fiala, M.; Krejci, J.; Int. J. Environ. Anal. Chem. 1996, 65, 139.

129. Su, Y. S.; Cagnini, A.; Mascini, M.; Chem. Anal. 1995, 40, 579.

130. Skládal, P.; Kaláb, T.; Anal. Chim. Acta 1995, 316, 73.

131. Zhou, D. M.; Nigam, P.; Jones, J.; Marchant, R.; J. Chem. Technol. Biotechnol. 1995, 64, 331.

132. Wang, J.; Nascimento, V. B.; Lu, J.; Park, D. S.; Angnes, L.; Electroanalysis 1996, 8, 635.

133. Neuhold, C. G.; Wang, J.; Cai, X.; Kalcher, K.; Analyst 1995, 120, 2377.

134. Newhold, C. G.; Wang, J.; Nascimento, V. B.; Kalcher, K.; Talanta 1995, 42, 1791.

135. Menil, F.; Lucat, C.; Debeda, H.; Sens. Actuators 1995, $B 25,415$

136. Park, C.; Yun, D. H.; Kim, S. T.; Park, Y. W.; Sens. Actuators 1996, B30, 23.

137. Lampe, U.; Gerblinger, J.; Meixner, H.; Sens. Actuators 1995, B25, 657 .

138. Tsai, P. P.; Chen, I. C.; Tzeng, M. H.; Sens. Actuators 1993, B14, 610.

139. Leonhard, V.; Fischer, D.; Erdmann, H.; Ilgenstein, M.; Koeppen, H.; Sens. Actuators 1993, B14, 530.

140. Azad, A. M.; Mhaisalkar, S. G.; Birkefeld, L. D.; Akbar, S. A.; Goto, K. S.; J. Electrochem. Soc. 1992, 139, 2913.

141. Beie, H. J.; Gnoerich, A.; Sens. Actuators 1991, B4, 393.
142. Cranny, A. W. J.; Atkinson, J. K.; Burr, P. M.; Mack, D.; Sens. Actuators 1991, B4, 169.

143. Lee, D. D.; Choi, D. H.; Sens. Actuators 1990, B1, 231.

144. Chu, W. F.; Leonhard, V.; Erdmann, H.; Ilgenstein, M.; Sens. Actuators 1991, B4, 321.

145. Holc, J.; Hrovat, M.; J. Mater. Sci. Lett. 1989, 8, 635

146. Vogt, M.; Shoemaker, E.; Turner, T.; Sens. Actuators 1996, B36, 370.

147. Ando, M.; Tsuchida, T.; Miura, N.; Yamazoe, N.; Nipon Kagaku Kaishi 1996, 4, 348.

148. Mizsei, J.; Lantto, V.; Sens. Actuators 1992, B6, 223.

149. Lantto, V.; Romppainen, P.; Rantala, T. S.; Leppavuori, S.; Sens. Actuators 1991, B4, 451.

150. Oyabu, T.; Osawa, T.; Kurobe, T.; Denshi Tsushin Gakkai Ronbunshi 1982, J65C, 615.

151. Hart, J. P.; Abass, A. K.; Anal. Chim. Acta 1997, 342, 199.

152. Napier, A.; Hart, J. P.; Electroanalysis 1996, 8, 1006.

153. Golovanov, V.; Solis, J. L.; Lantto, V.; Leppavuori, S.; Sens. Actuators 1996, B34, 401.

154. Haeusler, A.; Meyer, J. U.; Sens. Actuators 1996, B34, 388.

155. Montanaro, L.; Negro, A.; Pijolat, C.; Lalauze, R.; Annales de Chimie-Science des Materiaux 1995, 20, 399.

156. Yun, D. H.; Kwon, C. H.; Hong, H. K.; Shin, H. W.; Kim, S. R; Lee, K.; Sens. Actuators 1996, B35, 48.

157. Vlachos, D. S.; Skafidas, P. D.; Avaritsiotis, J.N.; Sens. Actuators 1995, B25, 491.

158. Tsai, P. P.; Chen, I. C.; Tzeng, M. H.; Sens. Actuators 1995, B25, 537.

159. Mishra, V. N.; Agarwal, R. P.; Sens. Actuators 1994, B22, 121.

160. Honore, M.; Lenaerts, S.; Desmet, J.; Huyberechts, G.; Roggen, J.; Sens. Actuators 1994, B19, 621.

161. Huusko, J.; Lantto, V.; Torvela, H.; Sens. Actuators 1993 , B16, 245.

162. Dutronc, P.; Carbonne, B.; Menil, F.; Lucat, C.; Sens. Actuators 1992, B6, 279.

163. Huusko, J.; Torvela, H.; Lantto, V.; Sens. Actuators 1992 , B7, 700 .

164. Lantto, V.; Rantala, T.S.; Sens. Actuators 1991, B5, 103.

165. Van Geloven, P.; Honore, M.; Roggen, J.; Leppavuori, S.; Rantala, T.; Sens. Actuators 1991, B4, 185.

166. Torvela, H.; Harkoma, A.; Leppavouri, S.; Sens. Actuators 1989, 17, 369 .

167. Sorita, R.; Kawano, T.; Sens. Actuators 1996, B36, 274.

168. Ansari, S. G.; Gosavi, S. W.; Gangal, S. A.; Karekar, R. N.; Ayer, R. C.; J. Mater. Sci-Mater. in Electron. 1997, 8, 23.

169. Ansari, S. G.; Boroojerdian, P.; Kulkarni, S. K.; Sainkar, S. R.; Karekar, R. N.; Aiyer, R. C.; J. Mater. Sci-Mater. in Electron. 1996, 7, 267.

170. Ansari, S. G.; Boroojerdian, P.; Sainkar, S. R.; Karekar, R. N.; Aiyer, R. C.; Kulkarni, S. K.; Thin Solid Films 1997, 295, 271.

171. Martinelli, G.; Carotta, M. C.; Sens. Actuators 1995, B23, 157.

172. de Angelis, L.; Riva, R.; Sens. Actuators 1995, B28, 25.

173. Martinelli, G.; Carotta, M. C.; Sens. Actuators 1993, B16, 363.

174. Lee, D.D.; Chung, W.Y.; Sohn, B.K.; Sens. Actuators 1993, B13, 252.

175. Chung, W. Y.; Lee, D. D.; Choi, D. H.; Sens. Actuators 1993, B14, 517.

176. Van Geloven, P.; Moons, J.; Honore, M.; Roggen, J.; Silic. Ind. 1990, 55, 81.

177. Huyberechts, G.; Van Muylder, M.; Honore, M.; Desmet, J.; Roggen, J.; Sens. Actuators 1994, B18, 296.

178. McCormac, T.; Cassidy, J.; Cameron, D.; Electroanalysis 1996, 8, 195.

179. Park, J. K.; Yee, H. J.; Kim, S. T.; Bios. Bioelectr. 1995, 10, 587. 
180. Dennison, M. J.; Hall, J. M.; Turner, A. P. F.; Analyst 1996, 121, 1769.

181. Yee, H. J.; Park, J. K.; Kim, S. T.; Sens. Actuators 1996, $B 34,490$.

182. Hitch, T. J. A. R.; Honeybourn, C. L.; J. Mat. Chem. 1996, 6, 285

183. Torvela, H.; Pijolat, C.; Lalauze, R.; Sens. Actuators 1991, B4, 445 .

184. Rauen, K. L.; Smith, D. A.; Heineman, W. R.; Johnson, J.; Seguin, R.; Stoughton, P.; Sens. Actuators 1993, B17, 61 .

185. Moneyron, J. E.; De Roy, A.; Besse, J. P.; Sens. Actuators 1991, B4, 189 .

186. Ansari, S. G.; Ansari, Z. A.; Kadam, M. R.; Karekar, R. N.; Aiyer, R. C.; Sens. Actuators 1994, B21, 159.

187. Ylinampa, A.; Lantto, V.; Leppavuori, S.; Sens. Actuators 1993, B14, 602 .

188. Kim, T. Y.; Lee, D. H.; Shim, Y. C.; Bu, J. U.; Kim, S.T.; Sens. Actuators 1992, B9, 221.

189. Gusmano, G.; Montesperelli, G.; Morten, B.; Prudenziati, M.; Pumo, A.; Traversa, E.; J. Mat. Process. Technol. 1996, 56, 589.

190. Qu, W. M.; Meyer, J. U.; Technisches Messen 1996, 63, 425.

191. Whightman, R. M.; Anal. Chem. 1981, 53, 1125A.

192. Bond, A. M.; Hendersonm T. L. E.; Thormann, W.; J. Phys. Chem. 1986, 90, 2911.
193. Bond, A. M.; Oldham, K. B.; Zoski, C. G.; Anal. Chim. Acta 1989, 216, 177.

194. Nascimento, V. B.; Augelli, M. A.; Pedrotti, J. J.; Gutz, I. G. R.; Angnes, L.; Electroanalysis 1997, 9, 335.

195. Augelli, M. A.; Nascimento, V. B.; Pedrotti, J. J.; Gutz, I. G. R.; Angnes, L.; Analyst 1997, 122, 843

196. Thormann, W.; van den Boch, P.; Bond, A. M.; Anal. Chem. 1985, 57, 2764

197. Scholze, J.; Hampp, N.; Bräuchle, C.; Sens. Actuators 1991, B4, 211

198. Silber, A.; Bisenberger, M.; Braeuchle, C.; Hampp, N.; Sens. Actuators 1996, B30, 127.

199. Craston, D. H.; Jones, C. P.; Williams, D. E.; Murr, N. E.; Talanta 1991, 38, 17.

200. Higgins, I. J.; McCann, J. M.; Davis, G.; Hill, H. A. O.; Zwansiger, R.; Treidl, B. L.; Birket, N. N.; Plotkin, E. V.; Eur. Pat. Applic. EP 127958 A 2, 1984.

201. Vaughan, P. A.; Scott, L. D. L.; McAleer, J. F.; Anal. Chim. Acta 1991, 248, 361.

202. Wang, J.; Chen, Q.; Anal. Lett. 1995, 28, 1131.

203. Jones, A. F.; McAleer, J. F.; Braithwaite, R. A.;Scott, L. D.; Brown, S. S.; Vale, J. A.; Lancet 1990, 335, 793.

204. Wang, J.; Nascimento, V. B.; Kane, S. A.; Rogers, K.; Smyth, M. R.; Angnes, L.; Talanta 1996, 43, 1903.

205. Silber, A.; Bisenberger, M.; Braeuchle, C.; Hampp, N.; Sens. Actuators 1996, B30, 127.

206. Turyan, I.; Mandler, D.; Anal. Chem. 1997, 69, 894. 